\title{
SAMMLUNG TUSCULUM
}

Herausgegeben von

Karl Bayer, Manfred Fuhrmann, Gerhard Jäger 


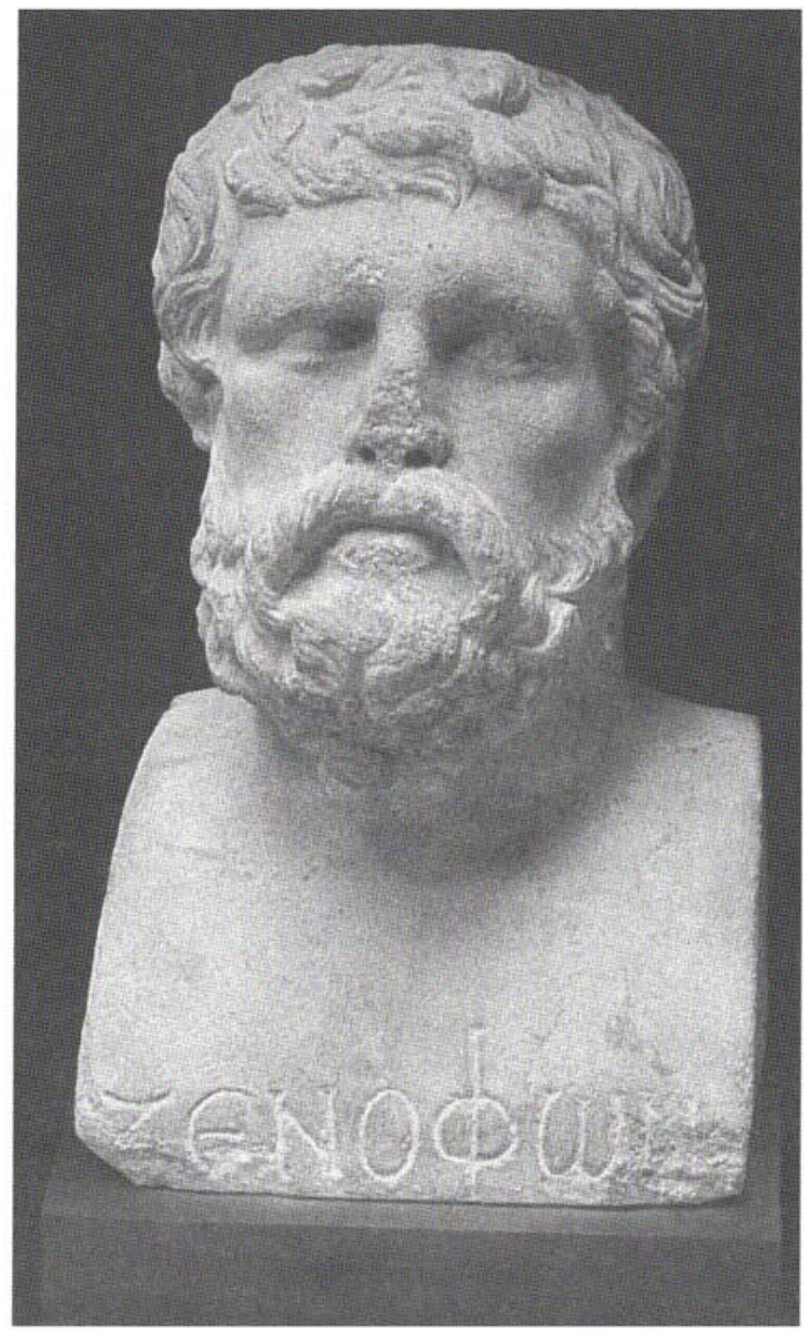




\title{
XENOPHON
}

\section{E R I N N E R U N G E N \\ AN SOKRATES}

\author{
Griechisch-deutsch \\ Herausgegeben von Peter Jaerisch
}

ARTEMIS VERLAG MUNCHEN UND ZURICH 
CIP.Kurztitelsufnahme der Deutschen Bibliothek

Xenophon:

Erinnerungen an Sokrates griech.-dt.

Xenophon. Hrag. von Peter Jaerisch.

4., durchges. Auf.

München ; Zürich : Artemis-Verlag, 1987.

(Sammlung Tusculum)

Einheitseacht.: Memorabilia

Bis 3. Aufl. im Heimeran-Verl., München

ISBN 3-7608-1638-X

NE: Jaerisch, Peter [Hrsg.]

Vierte, durchgesehene Auflage 1987

(c) 1987 Artemis Verlag München und Zürich,

Verlagsort München.

Alle Rechte, einschließlich derjenigen des auszugsweisen Abdrucks und der photomechanischen Wieder. gabe, vorbehalten. Druck: Laupp \& Göbel, Tübingen

Bindung: Realwerk G. Lachenmaier, Reutlingen Printed in Germany 